\title{
Study on Bilateral Interaction between Cultural Tourism and Cultural Inheritance
}

\author{
Linman Li \\ Chongqing University of Education, Chongqing, 400067, China
}

Keywords: Cultural tourism, Cultural inheritance, Bilateral interaction.

\begin{abstract}
Tourism is the carrier of culture, while culture is the soul of tourism. Sightseeing tour starts to be replaced by relaxing vacation now. The main purpose of tourism activities is to experience culture and folk custom of other places. This paper mainly analyzes bilateral interaction between cultural tourism and cultural inheritance.
\end{abstract}

\section{Introduction}

Tourism gets new life due to culture and culture is attractive to tourists. While utilizing and developing resources, developers of tourism resources can make local culture more charming, promote local economic development and stimulate the awareness of local people about local cultural protection so as to promote local culture. Therefore, it becomes a main way of tourism development to package tourism resources with culture and use tourism resources to carry local culture, which can integrate culture and tourism industry and realize transition of tourism industry. Once culture is linked to economy, distortion of cultural tourism will be caused under the abduction of economy and local culture will have stagewise, commercial and vulgarized features. The core issue of tourism research is how to prevent cultural distortion on the basis of inheritance.

\section{Connotations of cultural tourism}

With the development of times, people attach more and more importance to cultural transmission as culture is the soul of a nation and can make a nation have great cohesiveness and make people develop common cultural understanding and psychology. For example, the traditional Spring Festival of China can make Chinese people all over the world have homesickness. Therefore, there is a dense atmosphere of Spring Festival in Chinatown overseas. This is common cultural psychology. Even foreign friends are enthusiastic and curious about traditional Chinese culture and want to experience traditional eastern culture. With the development of Chinese economy and the improvement of national power, the world pays more attention to China and traditional Chinese culture becomes key culture that people concerns and gets popular among them. China is composed of 56 nationalities. Different nationalities have unique national customs and rich national culture to be experienced by tourists from various countries. China is vast. Different regions have rich local culture. With the improvement of national power of China, the state and people start to seek for Chinese cultural source and the soul of the strong nation. Relevant scholars have specifically pointed out that the period of future decades would be the era of traditional Chinese cultural renaissance. How to inherit and promote traditional Chinese culture is an issue to be resolved urgently in China.

Cultural tourism starts to be publicized and developed vigorously on this basis. Cultural tourism and tourist demand have certain relation. Tourist demand for tourism is changing to experience of allopatric folk custom from cursory glance. For example, tourists visited the Dai nationality for the Water-Sprinkling Festival of the local nationality but only watched people of the Dai nationality ten years ago. However, they now join people of the Dai nationality in the festival. People can have deeper understandings of local folk customs through cultural tourism. Therefore, cultural tourism emphasizes participation, entertainment and experience. Cultural tourism should not only present local distinctive culture to tourists, but also attract tourists for participation and experience of folk 
customs so as to transmit and promote local traditional culture. Tourism becomes the carrier of cultural transmission.

However, not all cultures can be transmitted through tourism. Only unique culture can be attractive to tourists and be developed through tourism. Therefore, the main purpose of cultural tourism is to make tourists understand cultural connotations of local nationality through experience, entertainment, sightseeing and leisure whereby local historic culture, modern culture and moral and ethical culture. Historic culture mentioned above mainly includes ancient site, cultural relic, ancient building and Historical Records etc. Modern culture main contains technical and artistic achievements. Folk culture mainly refers to festival celebration, life style and customs, wedding and funeral, clothing and worship ceremony of local people. Ethical culture mainly refers to local interpersonal communication etc.

\section{Cultural tourism and cultural inheritance}

Cultural tourism can inherit and protect culture to a certain extent and allow tourists to understand local culture through tourism. Moreover, local residents start to protect local culture consciously and exploit local culture deeply, thus changing local culture from cultural inferiority to cultural superiority.

\section{Cultural tourism can revive traditional Chinese culture}

With the development and progress of national economy, traditional Chinese culture has declined and traditional culture in some regions has been endangered, e.g. local language, music, clothing and art etc. Possession of a common language is the main feature of a nation. Though some nations have not invented character, they have their own language to prove their existence. Now, mandarin is used for communication among local nationalities. Most teenagers do not speak the language of their own nationality. There is a higher probability of children who do not speak national language. National language has gradually weakened. It is more obvious in the transformation of national dress. People in minority areas start to pursue for fashion in clothing. Only few minorities wear their own costume. National music and art also weaken obviously. Though Naxi ancient music in Lijiang is called as a music fossil alive, people who can perform it are almost old and few young people can play it. Therefore, a crisis in inheritance of local music and art occurs.

Visiting regions of nationality, tourists want to experience national culture, learn national language, appreciate national costume and music, have national special food and buy distinctive national specialties. For example, due to interest in national language, some tourists visit regions of nationality with the expectation of hearing national language and learning simple language. Therefore, to attract more tourists, tourist attractions in Chinese regions of nationality have to strengthen learning of national language and maintain traditional culture of the nationality after implementation of cultural tourism, meanwhile make cultural tourism develop and allow national regions to pay more attention to the exploitation and protection of national culture under the demand of tourists. People have started to exploit, develop and inherit endangered national handicraft art in China. It is thus clear that cultural tourism can revive traditional Chinese culture.

\section{Cultural tourism can maintain and protect historical site}

Countless ancient relics have been left in the history of civilization over thousands of years in China. As time goes and due to artificial or natural reasons, relics left by ancient people have been damaged. Most regions have realized urbanization with eradication of relics or construction of modern buildings on relics, thus making relics disappear. For example, famous historic culture street in Harbin had buildings of the Republic of China with a combination of Chinese and western elements. It was one of the few relics in China. This culture street was preserved most completely. Japanese scholars called this culture street as Chinese Baroque. In 2007, this historic culture street was removed and relics were damaged a lot.

Historic site and relics are key contents of development of cultural tourism. For example, tourists can experience the historic sense and cultural sense by touching the wall built by ancestors and 
viewing the place of residence of ancient people in a scenic spot. Protection of historical site can make it become important cultural tourism resources, attract more tourists and promote the development of local economy. Shanghai Xintiandi is most representative. It was originally used as real estate. Due to historic and ancient features of street, developers were required to change the development plan, retain Shikumen and protect the history. Now, the construction of Shikumen has not changed. Its exterior is retained and its interior is designed according to modern life, making people feel that they live in the previous century. It becomes a cultural tourism spot in Shanghai as well as a place where Chinese and foreign tourists gather. It is thus clear that cultural tourism can maintain and protect historical site

\section{Cultural tourism can stimulate the desire of local residents for protecting local culture}

Some cultural tourism regions have relatively backward economy and are weak in culture. Meanwhile, regions with backward economy accept the culture of regions with developed economy easily. Therefore, people in such regions have a sense of inferiority in their culture and think that their local culture cannot be compared with the culture of other regions. For example, when people communicate in Mandarin, residents who cannot speak Mandarin feel self-contemptuous and too shy to speak out. However, Guangdong and Shanghai people do not have any sense of inferiority in culture. They consider speaking Cantonese and Shanghai native language as a symbol of local regions and are proud of it. The main reason is that Guangdong and Shanghai are developed in economy and they have certain superiority in culture.

Positive development of cultural tourism can make local residents change from inferiority to superiority in culture. Developing cultural tourism, attracting a lot of tourists and making tourists have basic necessities of life in local regions can promote local economic development, provide more job opportunities for local residents and therefore improve their life quality and standard. Local residents will realize that tourists come to experience traditional culture of their nationality. Only with protection and inheritance of traditional culture of their nationality can they attract more tourists, promote economic development of local regions and improve living standard of people. Therefore, people in cultural tourism regions will have the consciousness of protecting traditional culture of their nationality so as to protect and inherit culture better.

\section{Cultural tourism can get financial support for cultural protection}

The development of cultural tourism mainly includes exploitation of traditional culture and maintenance and protection of historical sites so as to guarantee vital interests of local residents effectively. Such works requires certain financial support. Besides government support and social financing, cultural tourism scenic spots should also protect and inherit local traditional culture with their own force. Local government should comply with the development of the era, create cultural brands and attract more tourists so as to obtain more economic benefits and then protect local traditional culture.

\section{Cultural tourism and cultural distortion}

Cultural tourism can allow traditional culture of Chinese nationalities to be inherited and protected, but meanwhile will cause cultural distortion. Some regions package local culture into commodities. Such phenomenon will cause gradual loss of connotations of local culture and cultural distortion. Some regions present culture to tourists through stage. However, tourists only get performance culture and understand the processed art and culture. Such behavior is not real cultural transmission. Some regions change local culture arbitrarily in order to cater for tourists, thus causing cultural distortion.

\section{Cultural commercialization}

Cultural commercialization mainly means that culture is converted to commodities for sale. Cultural commercialization and cultural authenticity can coexist. Commercialization will not necessarily influence cultural authenticity and even can exploit and protect cultural authenticity. 
Cultural commercialization and authenticity can form an agreement to a certain extent, thus forming real commercialization. Cultural commercialization is a critical point of tourism development. Improper commercialization will cause low-level operation of cultural commercialization and cultural distortion due to the only purpose to meet economic needs. For example, silk ball in Jingxi, Guangxi. Jingxi County is the region with most people of Zhuang nationality. Silk ball is the most famous craftwork in Jingxi. Throwing silk ball is the most favorite activity of people of Zhuang nationality in Jingxi. It is generally carried out in singing fair. It is a main way for young men and women of Zhuang nationality to express love. However, silk balls are sold as craftwork in Jingxi. Cultural connotations of silk ball are gradually lost. It becomes a way to obtain benefits. Cultural distortion is caused. Therefore, though cultural package into commodities can improve the popularity of culture, it will cause cultural distortion easily.

\section{Stagewise feature of culture}

Stagewise feature of culture mainly means that culture is packaged into tourism products and transferred to the stage. The stage herein does not simply refer to stage performance. Instead, culture is packaged and placed in tourism products. Improper development of cultural stage will cause cultural distortion easily. For example, dragon-boat racing is a traditional project in Dragon Boat Festival, which contains certain cultural connotations. However, some regions make dragon-boat racing a local tourism performance program. It is performed whenever tourists have demands. Cultural distortion is caused. Let' s take Impression of Liu Sanjie for example. It is the largest live-action theatre of landscape which sings age-long folk songs and presents folk customs of Guilin landscape. It is stage performance of folk songs of Zhuang nationality. Many art skills are added in the performance process. Tourists only listen to the music under the stage and do not understand its real cultural connotations. Therefore, cultural distortion is partly caused.

\section{Conclusion}

Cultural tourism and inheritance are closely connected. While developing cultural tourism, developers should also guarantee cultural authenticity and avoid local cultural distortion and loss of significance of cultural protection and inheritance. Therefore, tourism developers should positively exploit traditional culture under the condition of guaranteeing cultural authenticity to attract more tourists and promote and inherit local culture while improving local economic benefit.

\section{References}

[1] Zhong Yuping. Study and Analysis on Red Tourism and Red Cultural Inheritance, Tourism Overview Monthly, 2015, (06):56.

[2] Liu Hongbo, Wang Xiaojing. Study on Interactive Development Mechanism of National Community Tourism Development and Intangible Cultural Heritage Inheritance, Productivity Research, 2015, (08):74-78.

[3] Yu Tao. Study on Interaction between Inheritance of Drum Dance of Miao Nationality in Hunan and Folk Cultural Tourism, Popular Literature, 2015,(08):38-39.

[4] Shi Yuding. Study on Interaction between Development of Tourism Industry and Inheritance of National Culture - Take Southeast Region of Chongqing for Example, Sichuan Drama, 2016,(11):152-156.

[5] Yang Fuquan. Discussion on “Great Shangri-la” Brand and Interactive Development of Culture and Tourism in Lijiang and Diqing, Humanistic and Social Science Edition of Journal of South-Central University for Nationalities, 2015,(01):18-23. 
[6] Zhao Yanyan, Sun Wenqin, Li Junheng. Study on Interactive Development of Traditional Sports Culture of Minorities in Yuanjiang County and Tourism Economy, Contemporary Sports Technology, 2015,5(11):173.

[7] Wang Yaqiong, Luo Xijuan, Zhang Xingqi et al. Study on Interactive Development of Original Traditional Sports Culture of Maonan Nationality and Regional Tourism Economy, Journal of Qiannan Normal College for Nationalities, 2016,36(02):11-15.

[8] Xing Hongliang, Yang Xi. Study on Interaction between Intangible cultural Heritage Protection of Xibe Nationality in Liaoning and Tourism Development, Packaging Engineering, 2017,38(04):51-55. 